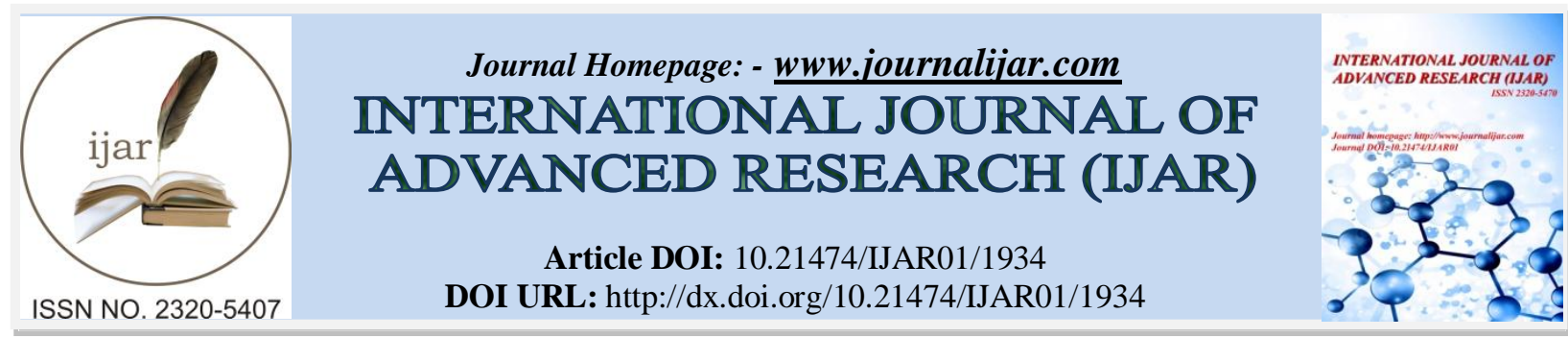

RESEARCH ARTICLE

\title{
EVALUATING ACQUIESCENCE OF FLEXIBLE REMEDIATION EXPERIMENTAL DESIGN SUSTAINING LAKE WATER RESOURCE QUALITY.
}

Shekhar Salunke ${ }^{1}$ and Chavan B.L ${ }^{2}$.

1. Dept of Environmental Science, Solapur University, Solapur, MS, India.

2. Dept of Environmental Science, Dr. B.A.M. University, Aurangabad, MS, India.

\section{Manuscript Info}

Manuscript History

Received: 12 August 2016

Final Accepted: 16 September 2016

Published: October 2016

Key words:-

Aquatic bioengineering, remediation, sediment barrier, ecosystem, restoration.

\section{Abstract}

The non-point source pollution (NPS) happens when water budges pollutants from the land towards the water bodies. The sediments and nutrients are recognized as the most common such (NPS) pollutants and when released into the receiving waters as a result of soil erosion can become NPS pollution. Soil erosion is a major issue and efforts to reduce the impacts of various activities on sedimentation are the essence of the moment. Once the cause is determined, a low-cost, innovative solution should be thought of. Various compost filters have been experimented, however, Eicchornia leaf biomass filters are not yet reported to have been employed for the purpose. The rationale of the study was to estimate effectiveness of Eicchornia leaf biomass filter sleeves as a sediment barrier at the lake waters. Eicchornia leaf filter sleeves (Sun dried premature Eicchornia leaf biomass fills) crammed in an IS 16008 (2012)- tubular mesh sleeve as a linear land based treatment filter were investigated by us earlier and the results have been published. The earlier studies depicted effective percent reduction of sand $89 \%$, TSS $68 \%$, silt $56 \%$, turbidity $51 \%$, and clay by $18 \%$. As a part of extended study, the serrated model was employed and it resulted in percent reduction of sand $90 \%$, TSS $72 \%$, silt $69 \%$, turbidity $62 \%$, and clay by $28 \%$. The serrate based application of the sleeve did not show any significant increase in the sand filtration in comparison with the linear based model. The serrate based model resulted in a increase in the percent reduction of total suspended solids, slit, turbidity and comparatively more of clay. The probable reason confirmed is due to the increase in the runoff slope length. Thus it can be concluded that the serrate mode of application of Eicchornia biomass sleeve is more effective in comparison with the earlier linear based model. However we arrive at a conclusion that the selection and application of the linear based or serrate based Eicchornia biomass sleeves should be site specific. Either of the methods indicates a promising reduction in the silt loads into the lake waters. The Eicchornia biomass sleeve application should emerge as a novel, cost effective, and environmentally friendly method of silt filtration. This serves twofold function one to eradicate the notorious weed and to diminish soil erosion and habitat destruction to protect sensitive wetlands, water bodies, wildlife habitat, and ecosystems in a

Corresponding Author:- Shekhar Salunke. Address:- Dept of Environmental Science, Solapur University, Solapur, MS, India. 
paramount environmental friendly approach. In continuation to the earlier studies it is anticipated that by studying the processes of erosion and sedimentation, innovative sediment control and management attempts provide examples of effective erosion and sediment control strategies. Such attempts should support to plan and implement at the lakes aiding conservation and restoration activities for sustainable environment.

Copy Right, IJAR, 2016,. All rights reserved.

\section{Introduction:-}

Wetlands are vibrant self sustaining stream passageways having natural stream channels. The stream channel, the wetland plains, vegetation collectively assist the system to sustain a dynamic equilibrium. These systems serve to minimize flood climax liberations, soak up and help cycling, transportation of the nutrients, further offer habitat for wetland vegetation and faunal population. The plant communities change temporally and spatially as a response to the water and sediment inputs through the stream corridors. Whereas the vigorous stream transports of sediments through the stream channels the plains and its wetlands traps and amass sediment through the inflows and further release the same during the episodes of stable adjustment in channel and the plain geometry (Fig.1). This dynamism provides the spatial and temporal changes in plant community and provides a system with multiple stages of succession which maximizes the available habitat niches. Wetlands have reduced their function because of multiple factors. Governing water source and hydrodynamics seem to be the minor parameters in the Hydro-Geomorphic Classification System. The classes of wetlands in this regards are epi-saturated and endo-saturated (Fig.2). These categories apply to the stable unaltered state. Epi-saturated wetlands have the surface water for more than 15 days during the growing season. Wetland hydrology due to endo-saturation is defined as the presence of ground water within 6 to 12 inches of the ground surface for more than 15 days during the growing season (USACE 1987). In the endo-saturated wetlands the hydrology is supported mainly by the ground water surface in the alluvial aquifer. The system is usually dominated by coarse grained soils in the stream sediment load and flood plain. These highpermeability soils permit the ground water table to respond readily to changes in the stream water surface profile. The ground water surface is the local ground water table. During periods of high flow in the stream, the ground water gradient slopes into the flood plain, recharging the aquifer. As the stream hydrograph recedes, the gradient reverses, and stored ground water provides long-term base flow for the stream (fig.1). During the period of the resource inventory phase of planning, it is imperative to establish and confirm if the stream wetland system is stable or is poignant from stability, or toward stability. In regards to the stream channel, this seems to be an effective tool.

The research embarks with an intention to portray a technique to curtail erosion around the lakes and thereby diminish the impacts of sedimentation. It is anticipated that by studying the processes of erosion and sedimentation, innovative sediment control and management attempts provide examples of effective erosion and sediment control strategies. Such attempts should support to plan and implement at the lakes aiding conservation and restoration activities for sustainable environment. 


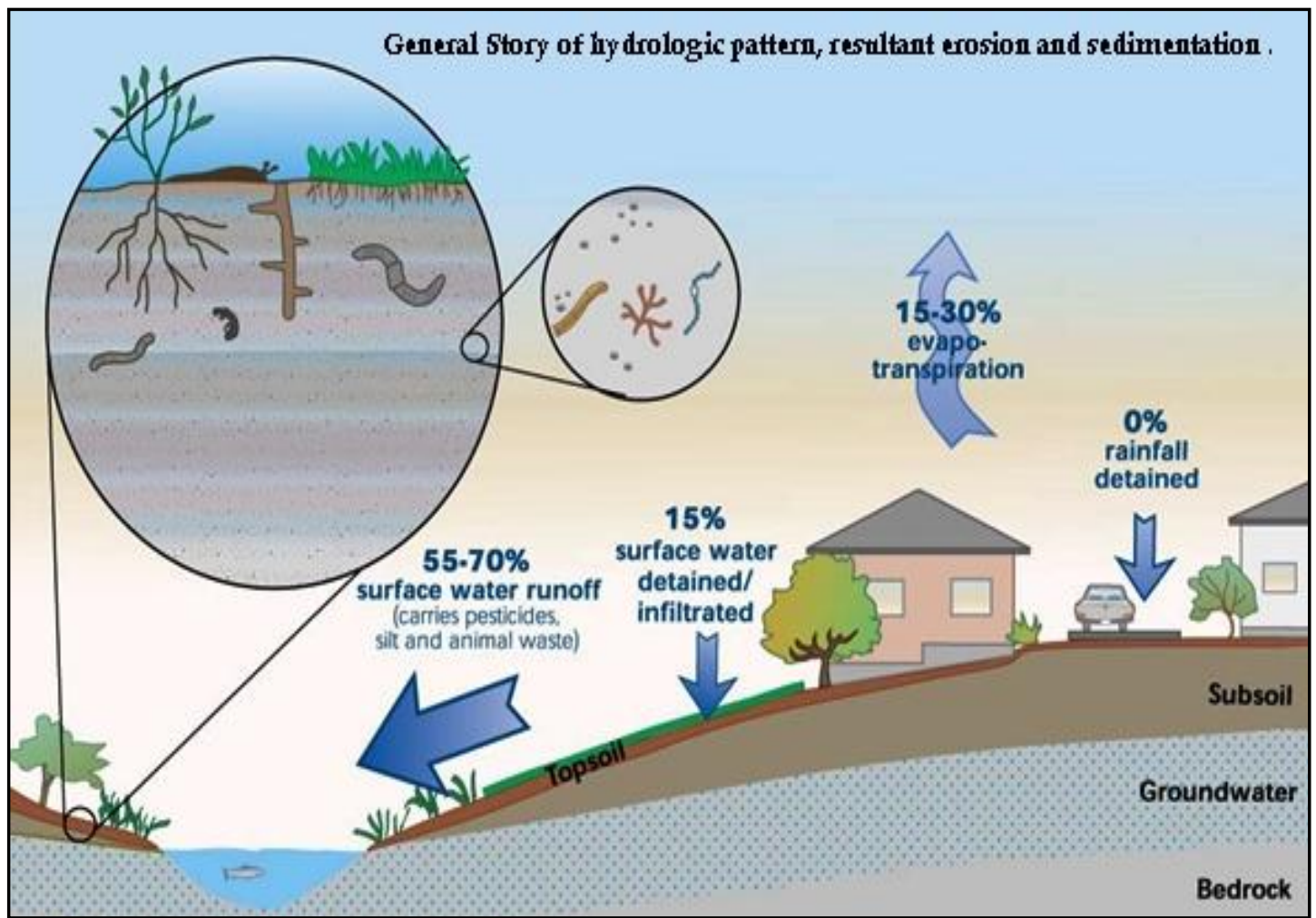

Fig 1:- General Story of hydrologic pattern, resultant erosion and sedimentation.

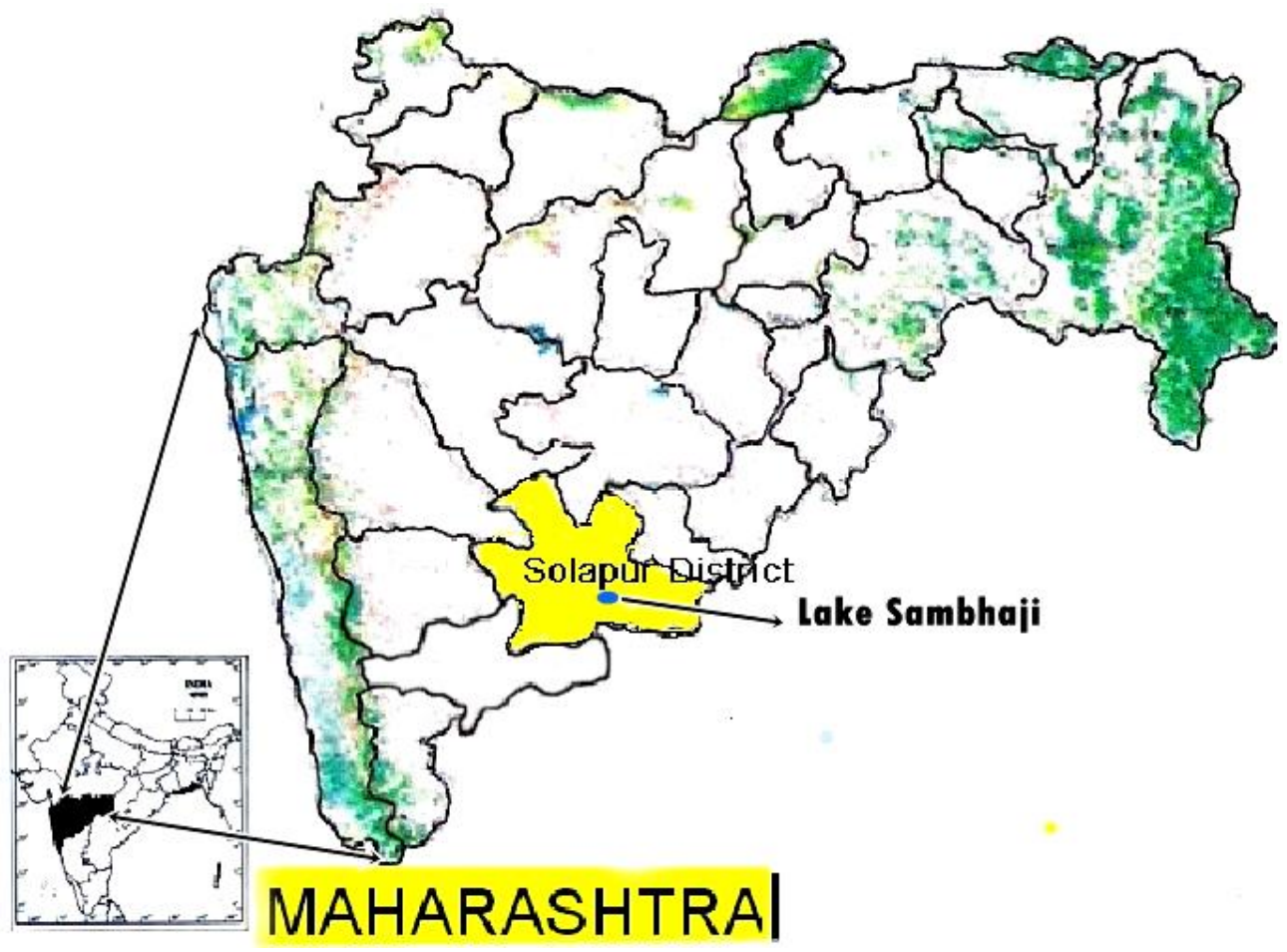

Fig. 2:- Map of Maharashtra State Showing District Solapur And The Study Area. 


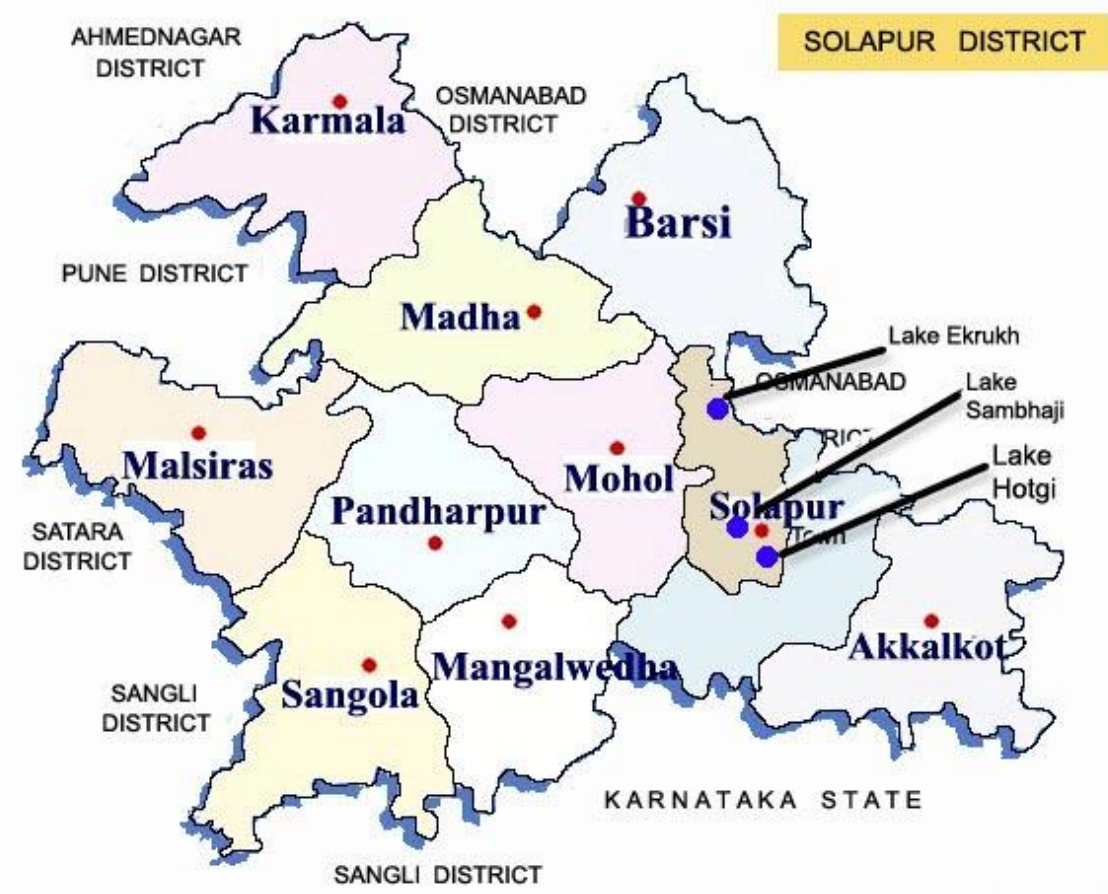

Fig 3:- Map of Solapur district State showing the study area.

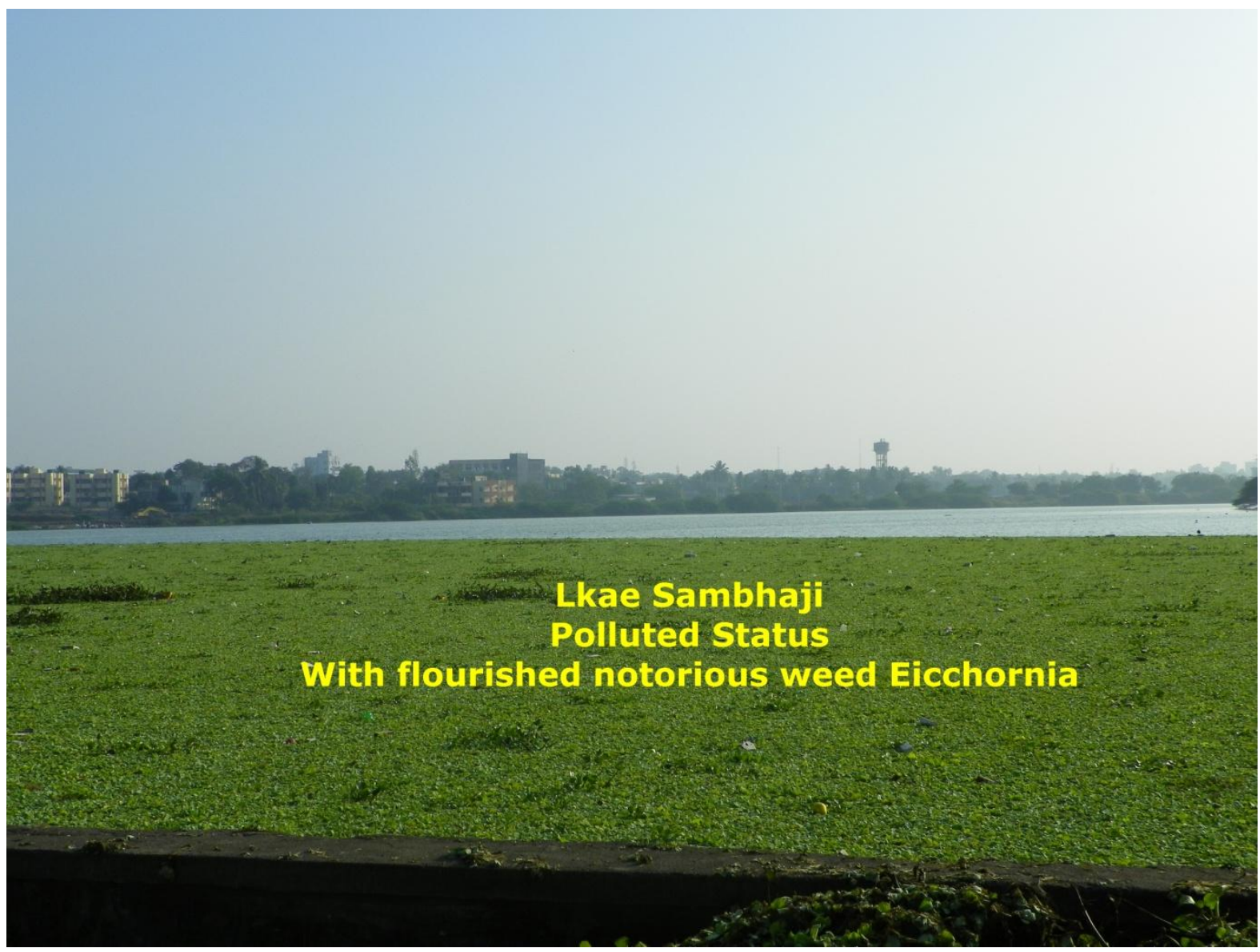

Fig 4:- Lake Sambhaji; pollution Status with flourished Eicchornia sp. 


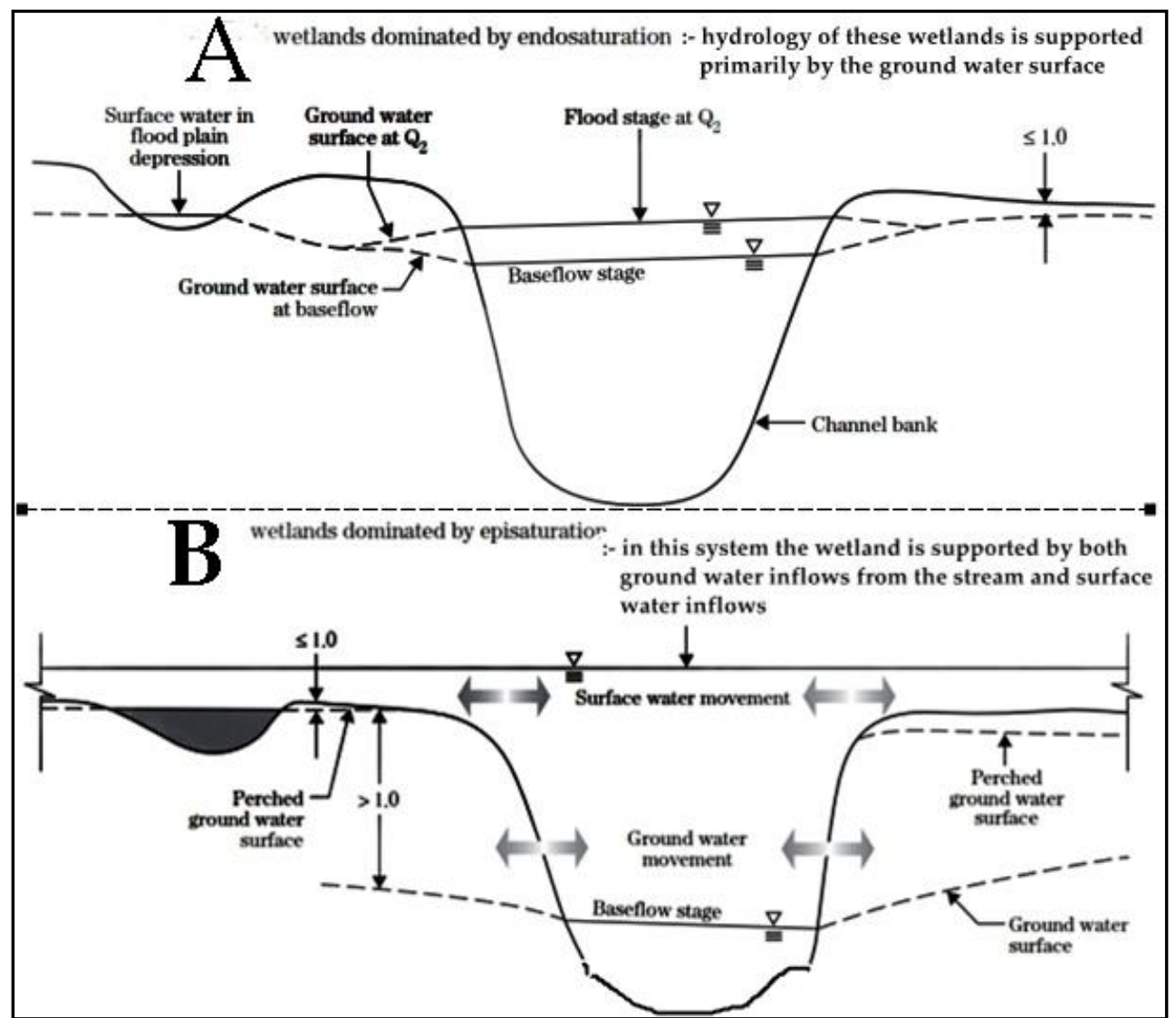

Fig 5:- Diagrammatic view of the Epi - Saturated \& Endo -Saturated Wetlands.

\section{Type I-Stable}

In this system channels are in a state of long term dynamic equilibritum. The sediment transport of the system is in balance with the sediment stipply from the watershed. The channel has dy namic connectivity with its flood plain.

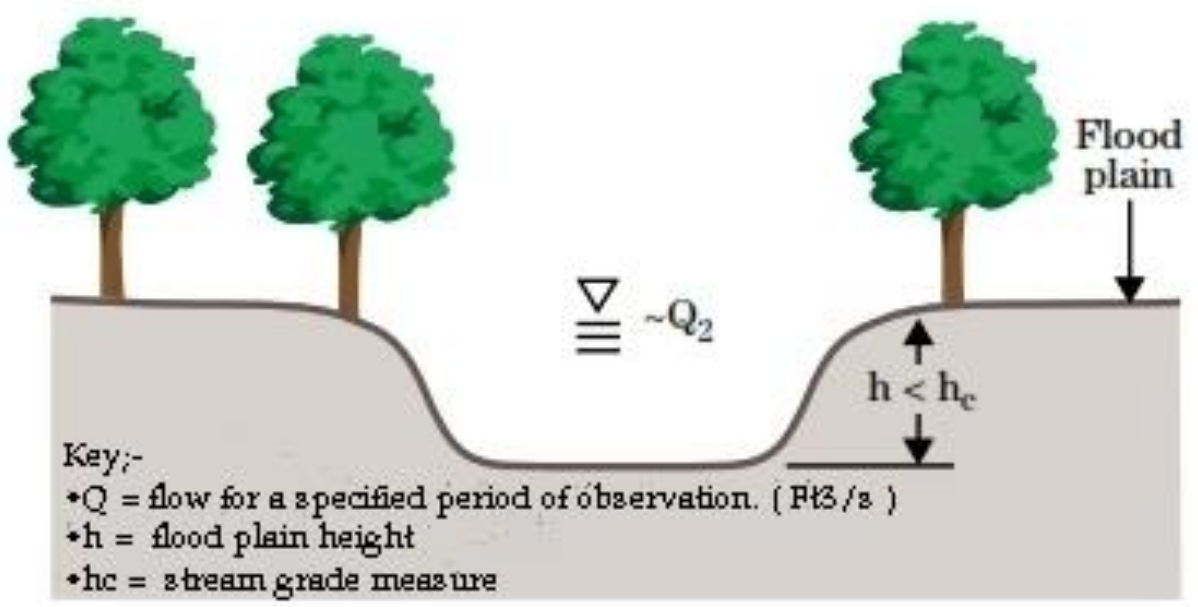

Fig 6:- Type - I Stable ( Source USACE- May 2008) 


\section{Type II-Incision}

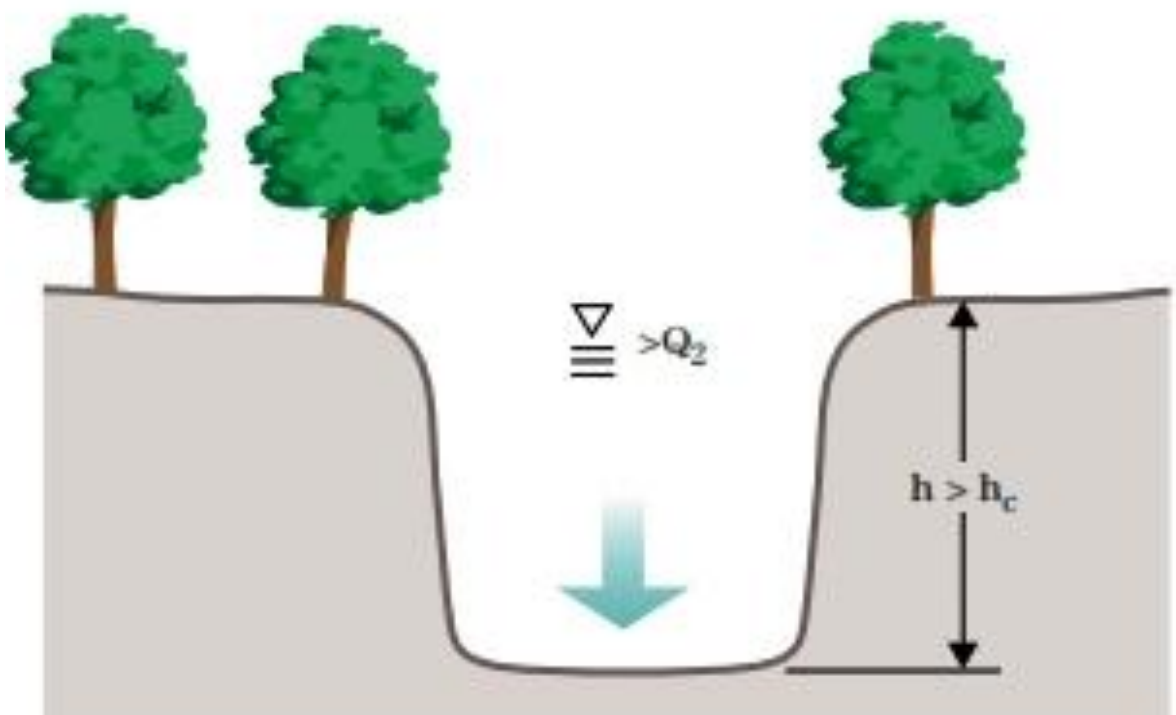

In type II - Incision- are actively incising. Straightening of the channel within the reach or downs tream causes increase in stream grade that induces a higher tractive stress on the channel bed allowing it to move the sediments downs tream at a rate greater than its sediment supply.

Fig 7:- Type - II Incision ( Source USACE- May 2008).

\section{Type III-Widening}

The atream aystem reacts by attempting to bulld a new actlve flood platn at the new lower level Tractive stress forces begin to attack the channel banks as the actye channel whidens.

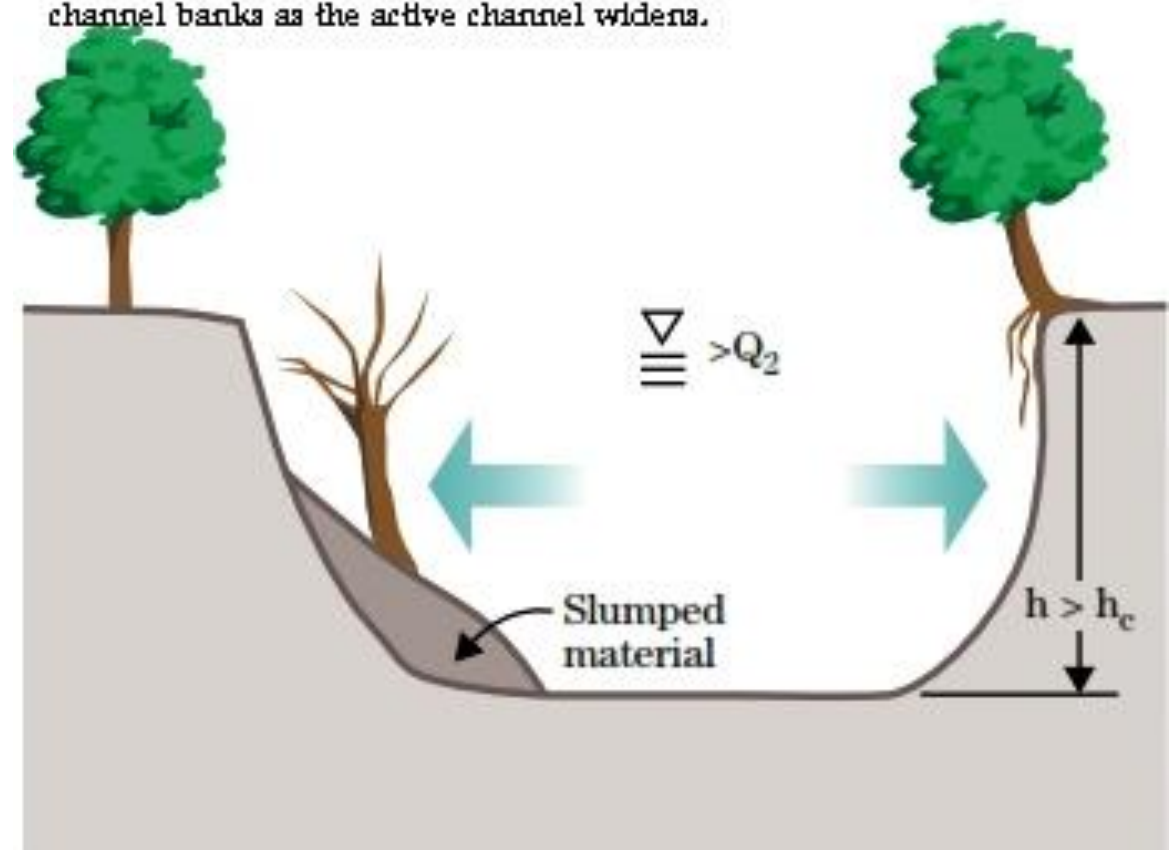

Fig 8:- Type - III Widening (Source USACE- May 2008) 


\section{Type IV-Depostion/stabilizing}

Type IV is a period of flood plain development.

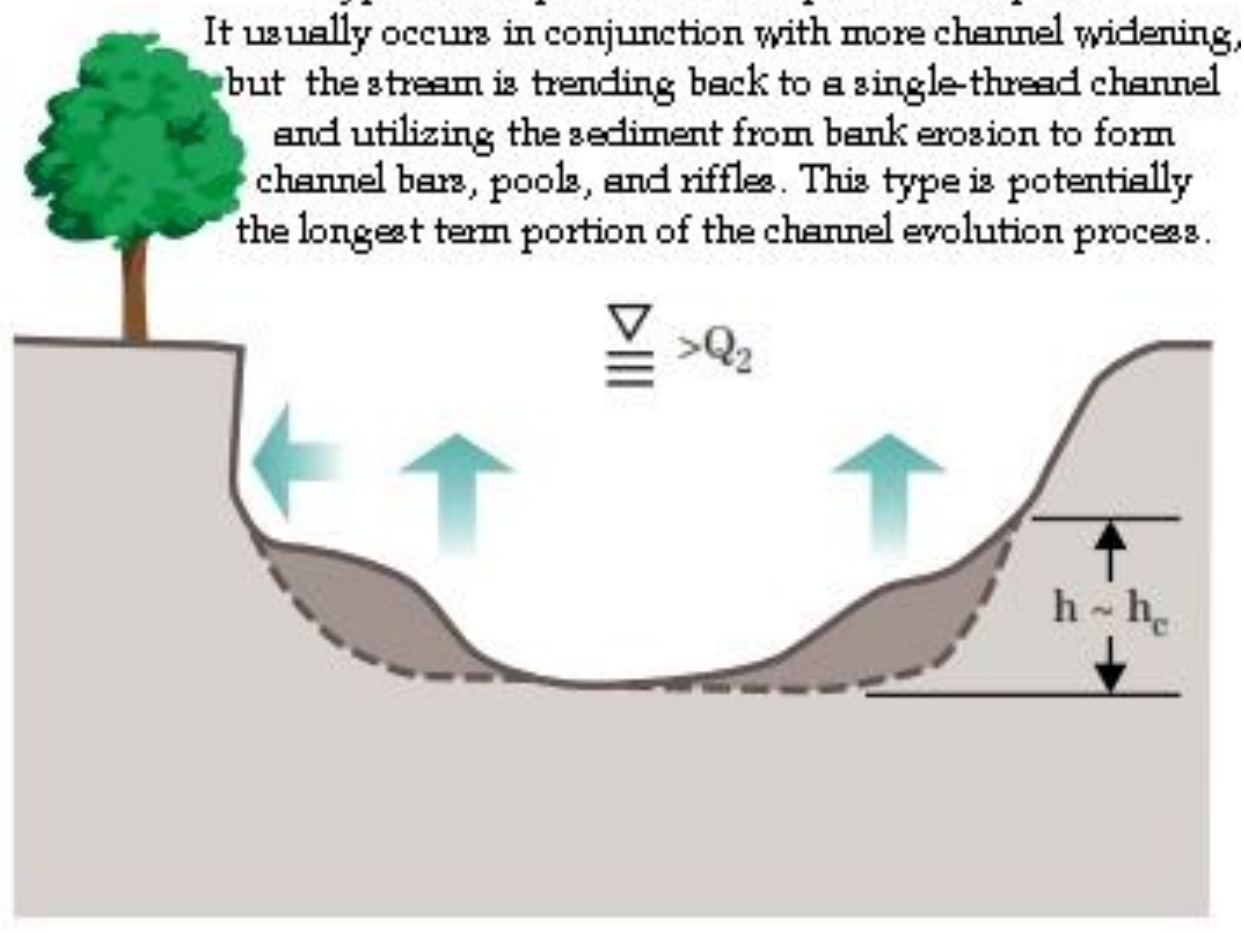

Fig 9:- Type - IV Deposit / Stabilizing (Source USACE- May 2008)

\section{Type V-Quasi-equilibrium stable}

Type $V$ is the same as type I, except the entire stream

flood plain cross section is now at a lower lendscape

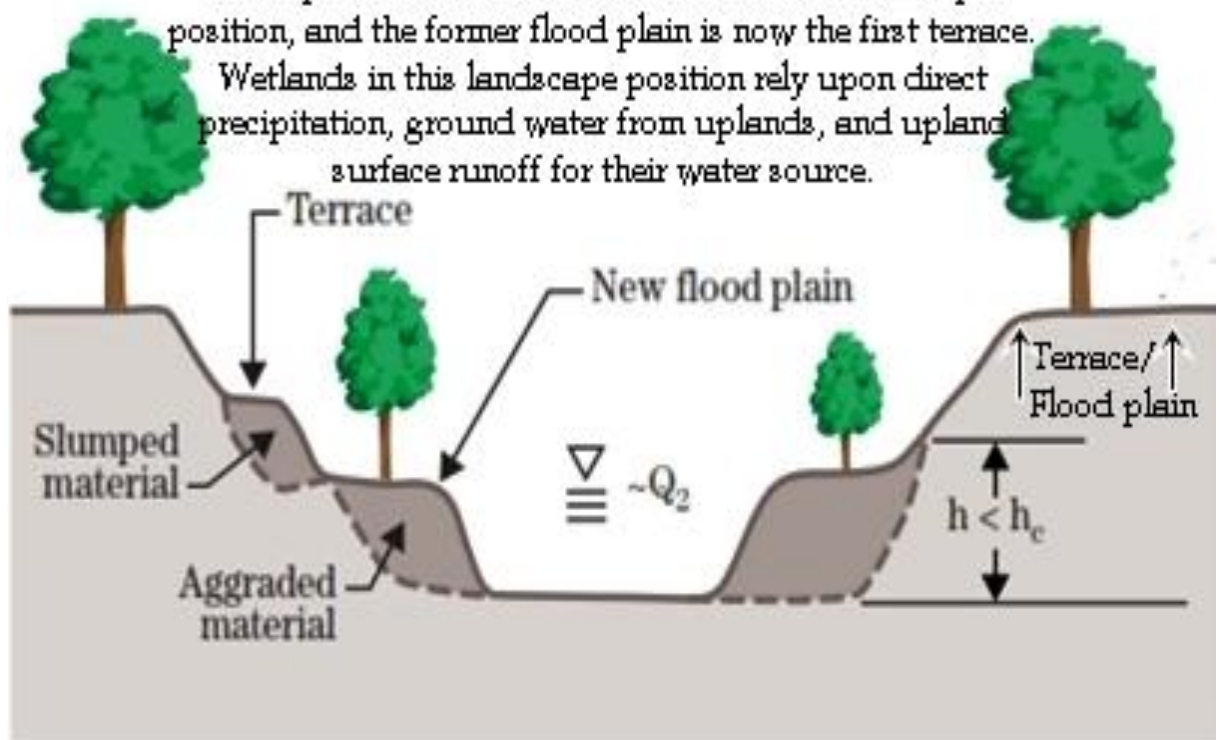

Fig 10:- Type - V Quasi - equilibrium stable (Source USACE- May 2008) 


\begin{abstract}
About the study area and the experimental site:-
The study area, Lake Sambhaji is located at $3.6 \mathrm{~km}$, approximately at the city Solapur of Maharashtra State, India. It is a natural lake with an area of $25.35 \mathrm{ha}$. The lake is located geographically, between Latitude: $\mathrm{N} 17^{\circ} 38^{\prime} 55.61$ \& Longitude: $\mathrm{E} 75^{\circ} 54^{\prime} 13.9$, an altitude of $491.94 \mathrm{~m}$ msl. (Fig. 2, 3, 4, 11, 16). The water from the reservoir is being used for irrigation for forestry and fisheries. The lake suffers a huge sedimentation problems and thereby causing problems of the soil erosion, sedimentation and surface water turbidity. Soil erosion is a major land management issue due to stringent regulations on water quality and efforts to reduce the impact of various activities on sedimentation. Once the cause of the problem was determined, and a low-cost, innovative solution was thought of. The research focused on the assessment and solution for the erosion problem at the study area. This directed us to take up immediate action towards preventing siltation or sedimentation at the lake in a naturally directed innovative approach. Hence a blend of natural processes and traditional engineering solutions, has been developed and tested through the research project
\end{abstract}

\title{
Materials and methods:-
}

Data inventory through aerial photo (fig.11) of the site under investigation including the adjacent areas was used to recognize significant site distinctiveness, to develop the plan to control sedimentation along with additional as features of adjacent areas. Contour elevations pertaining to the slope and at intervals of one to five feet were studied through a topographic map and LISS-III imageries (Fig. 13, 14, 15), of the site under investigation. The study also considered the existing patterns of drainage with both; upstream and downstream areas adjacent to the proposed site. The vegetation cover on the site was also studied that included herbs, shrubs and trees with a special reference of the grassy areas and the exposed surface of the soil. To determine the method of erosion control technique intended to be employed on the site the predictable runoff volumes and velocities were computed. The carrying capacity of the streams on the site receiving runoff was surveyed to establish the mode of sedimentation control before the water leaving the site. The length of slope and steepness was studied where the steeper and longer slope that tends to increase the erosion potential due to runoff flow was preferred for the implementation of the sleeve project. Adjoining areas with analogous steepness were clustered.

The design and layout was prepared and installed following the guidelines provided for the design and installation following the Maryland Standards and Specifications for Soil Erosion and Sediment Control, 2011, (Fig.17), (UNEP- Caribbean Environment Programme); CEP Technical Report No. 32, 1994 \& Iowa Construction Site Erosion Control Manual, Iowa Department of Natural Resources (IDNR), 2006. For the Linear based Eicchornia sleeve application, for the sleeve preparation, primarily premature Eicchornia leaf filter (Sun dried Eicchornia leaves ) filled in a IS 16008 (2012)- tubular mesh sleeve as a linear land based treatment filter to study the efficacy of filtration ability of sediments (primarily) (and soluble pollutants;- further contemplation). The sleeve made up of a U.V. stabilized shade net of 150 GSM of high strength) Net specifications- (Commercially available U.V. stabilized shade net of 150 GSM of high strength, manufactured from HDPE granules, of Type III, having shading factor of 90 percent., with mass $140, \mathrm{~g} / \mathrm{m}^{2}$, satisfying retention of breaking strength $85 \%$ percent of original actual value of the fabric after UV exposure, $1.70 \mathrm{~mm}$ width of the tape used in the fabric, and linear density of the tape 40 Tex (400 Denier). Width after ravelling $=50 \mathrm{~mm}$, Gauge length $=200 \mathrm{~mm}$, with 290 average breaking strength of shade net fabric (Ravelled strip method), both wrap way and weft way. The earlier studies were conducted applying the sleeves in a linear based model, where the sleeves were placed on contours, perpendicular to rill or gully water flow channels, five feet i.e. about 1.5 meters ahead of the slope toe permitting sediment deposition, accumulation of runoff and maximum storage of sediments on the prepared ground surface. Eicchornia biomass filter sleeves were installed at $8 \% / 12 \% / 18 \%$ and $24 "$ as the slope identified was between $2 \%$ to $5 \%$. These were placed across the channel in ' $\mathrm{V}$ ' formation in a straight line. The sleeves were found to physically filter coarse and fine sediments and opined to chemically filter some soluble pollutants that are to be analyzed (a contemplated

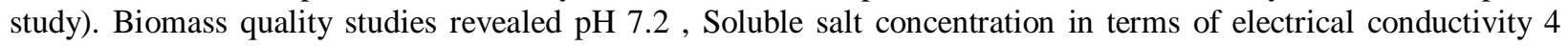
mmhos/cm , Moisture content percent, wet weight basis 52, Organic matter content percent, dry weight basis 48, agreeable with the specifics stated by the U.S. Environmental Protection Agency (2006).

The size of the percent particles passing through the sleeve mesh, was recorded on dry weight basis. Rainfall simulation was conducted in the pilot project $0 \mathrm{f} 3.1 \mathrm{inch} /$ hour for 1 hour in a plot size of 3' wide and 16' long. Sediments were found to be trapped in varying pore spaces and sizes. For the installation of Serrate based Eicchornia sleeve application the same sleeves were used as mentioned above however the application was done in accordance to the rise and run measuring 2 and 4 feet respectively. A diversion was provided to the overland flow to a suitable outlet from the top of the serrate cuts. The serration steps were in agreement to the dimensions of rise and 
run, measuring 2 feet vertical for rise and horizontally 4 feet for run confirming the slope not steeper than the ratio of 2:1 at the non-rock site under investigation The line grade and cross section of the designed temporary serrated slopes were confirmed to be stabilized following an incubatory period of 7 days towards stabilization period as approved by the sediment control plan. (Table-1, Fig.12). The slope gradients were categorized into the ranges of soil erodbility as: $0 \%$ to $3 \%$ having low erosion potential, $3 \%-8 \%$ having medium erosion potential. $0 \%$ to $3 \%$ was recorded to be about 280 feet in the study area where the erosion potential was found to be more serious, however the slope length at certain study area exceed the $3 \%$ to $8 \%$ beyond 148 feet (Table-1, Fig.12). Hence primarily the sleeve application was chosen to be installed at the range of 0-3\% slope of length 280 feet.

The study area indicated existence of natural drainage patterns, consisting of depressions and overland flow, which aided to locate the possible critical areas where concentration of water occurred. The ground cover did not indicate any grass ground cover portraying the possibility of erosion. Thus the sleeve installation was considered at this site as it was assumed to reduce the erosion potential. The velocity of flowing water was found to be inadequate towards the transport of sediment as it came across the barriers towards the movement of sediments. Larger particles were found first to be deposited during reduced flow velocities as against the finer sediments which did not settle.

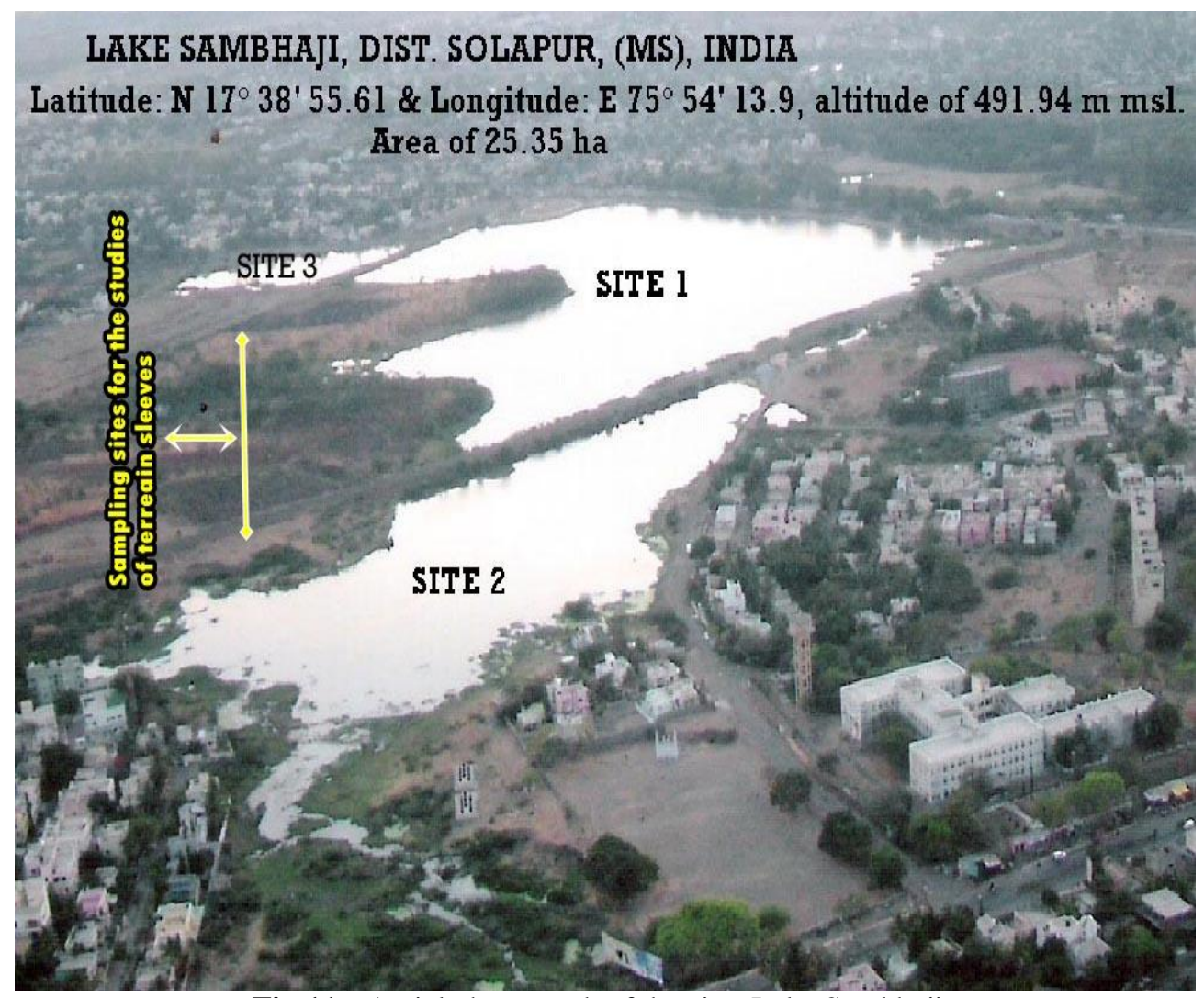

Fig 11:- Aerial photograph of the site- Lake Sambhaji.

Table 1:- Slope studies of the selected site.

\begin{tabular}{|l|l|l|}
\hline SITE & SLOPE & \% \\
SAMPLED & DEGREES & SLOPE \\
\hline S1 & 1.44 & 2.51 \\
\hline S2 & 1.49 & 2.60 \\
\hline S3 & 1.50 & 2.61 \\
\hline S4 & 1.21 & 2.11 \\
\hline S5 & 1.16 & 2.02 \\
\hline S6 & 0.99 & 1.72 \\
\hline S7 & 0.83 & 1.44 \\
\hline S8 & 0.85 & 1.48 \\
\hline
\end{tabular}




\begin{tabular}{|l|l|l|}
\hline S8 & 0.94 & 1.64 \\
\hline S10 & 1.34 & 2.33 \\
\hline S11 & 1.76 & 3.07 \\
\hline S12 & 1.72 & 3.00 \\
\hline S13 & 1.58 & 2.75 \\
\hline S14 & 0.50 & 0.87 \\
\hline S15 & 0.38 & 0.66 \\
\hline S16 & 2.05 & 3.57 \\
\hline S17 & 1.58 & 2.75 \\
\hline S18 & 0.36 & 0.62 \\
\hline
\end{tabular}

$* \mathrm{~S}=$ sampled site at site 1

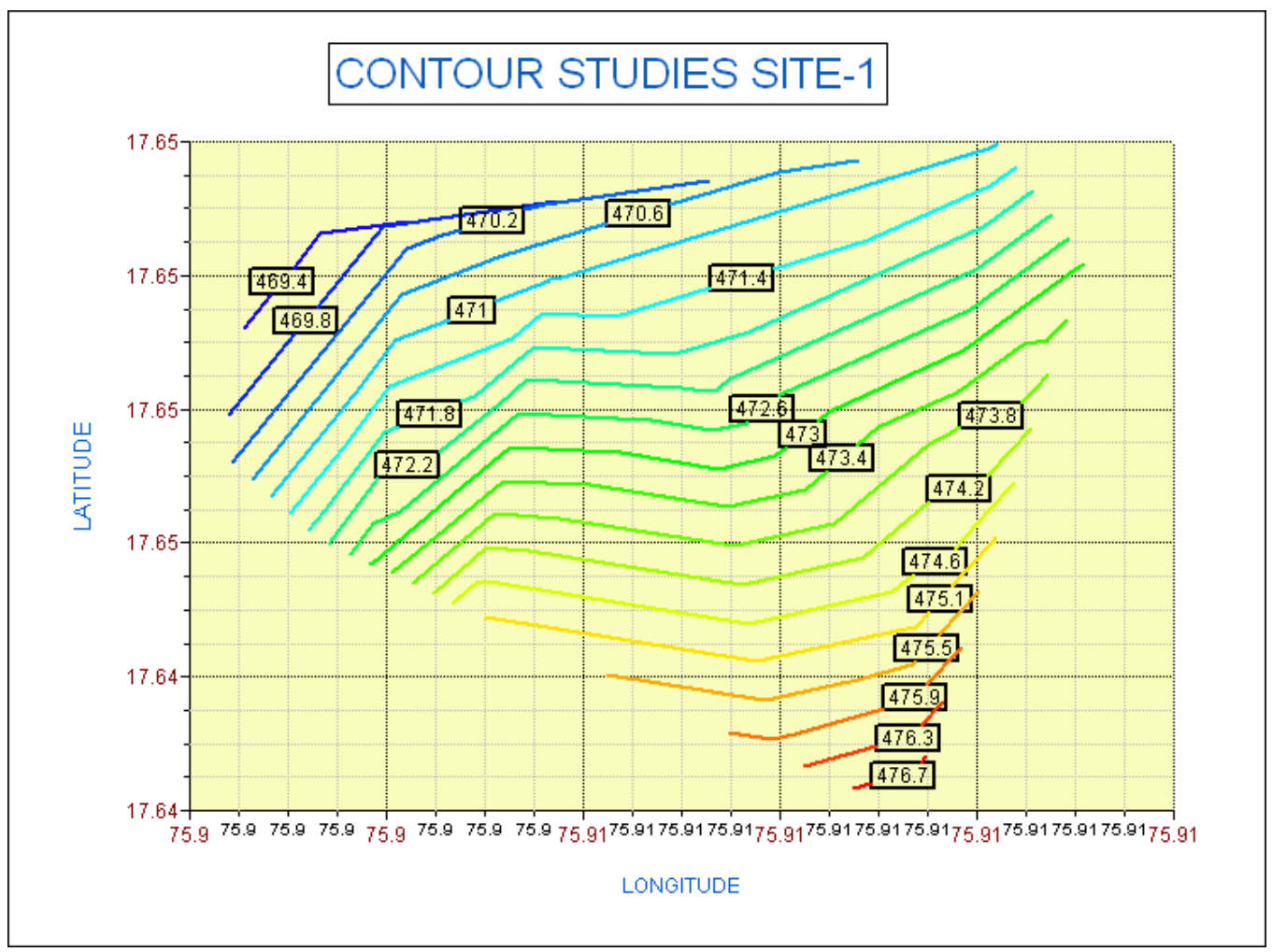

Fig 12:- Contour studies of the site. 


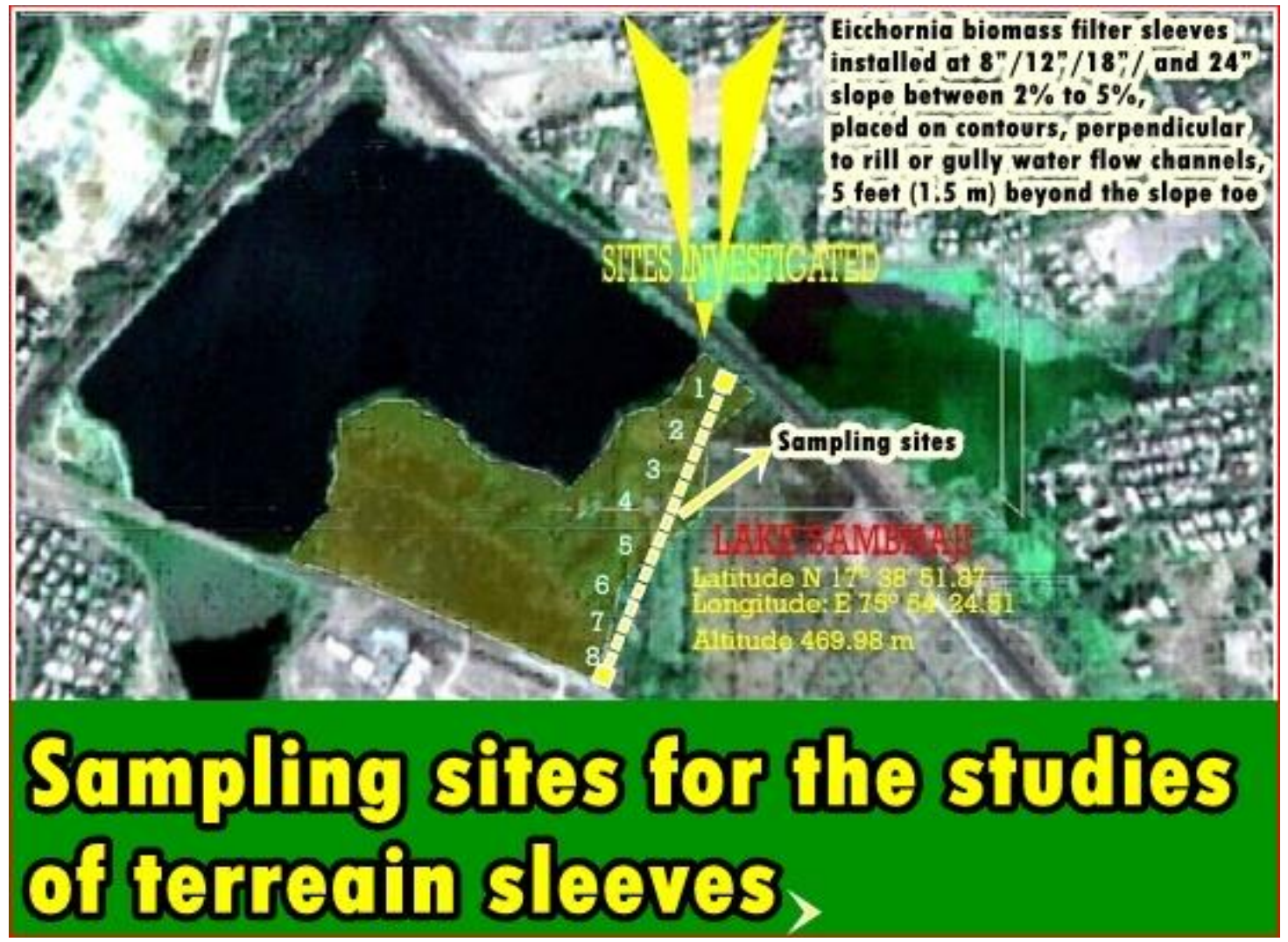

Fig 13:- Selection of sampling sites for the studies of terrain sleeve application.

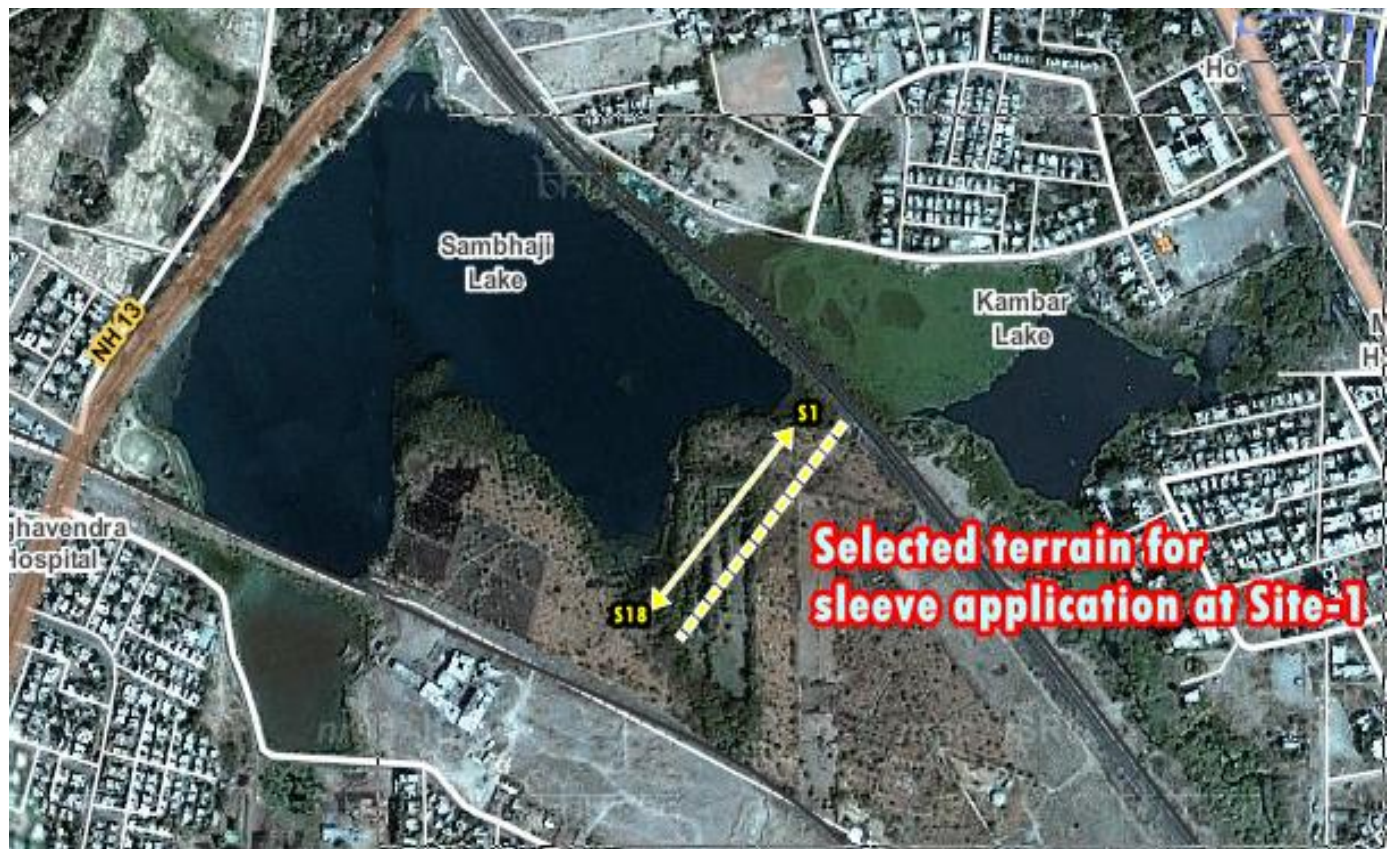

Fig 14:- (0-0.20 KM) 75.90, 17..65, Site studies of lake Sambhaji (Geo-platform ISRO) 


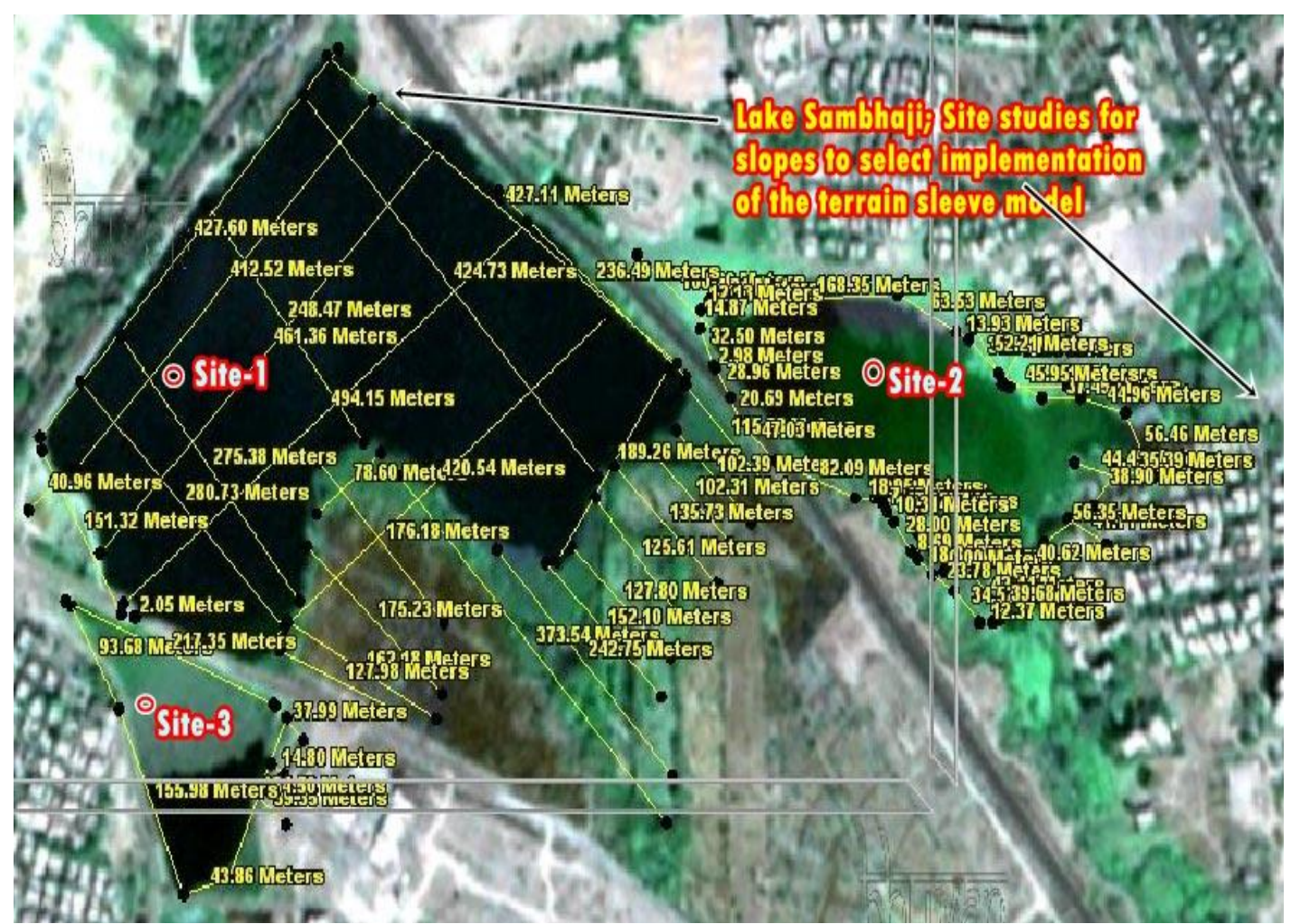

Fig 15:- Site studies of Lake Sambhaji through LISS III imagery.

(Demarcating loci at the site for experimental layout \& installation)

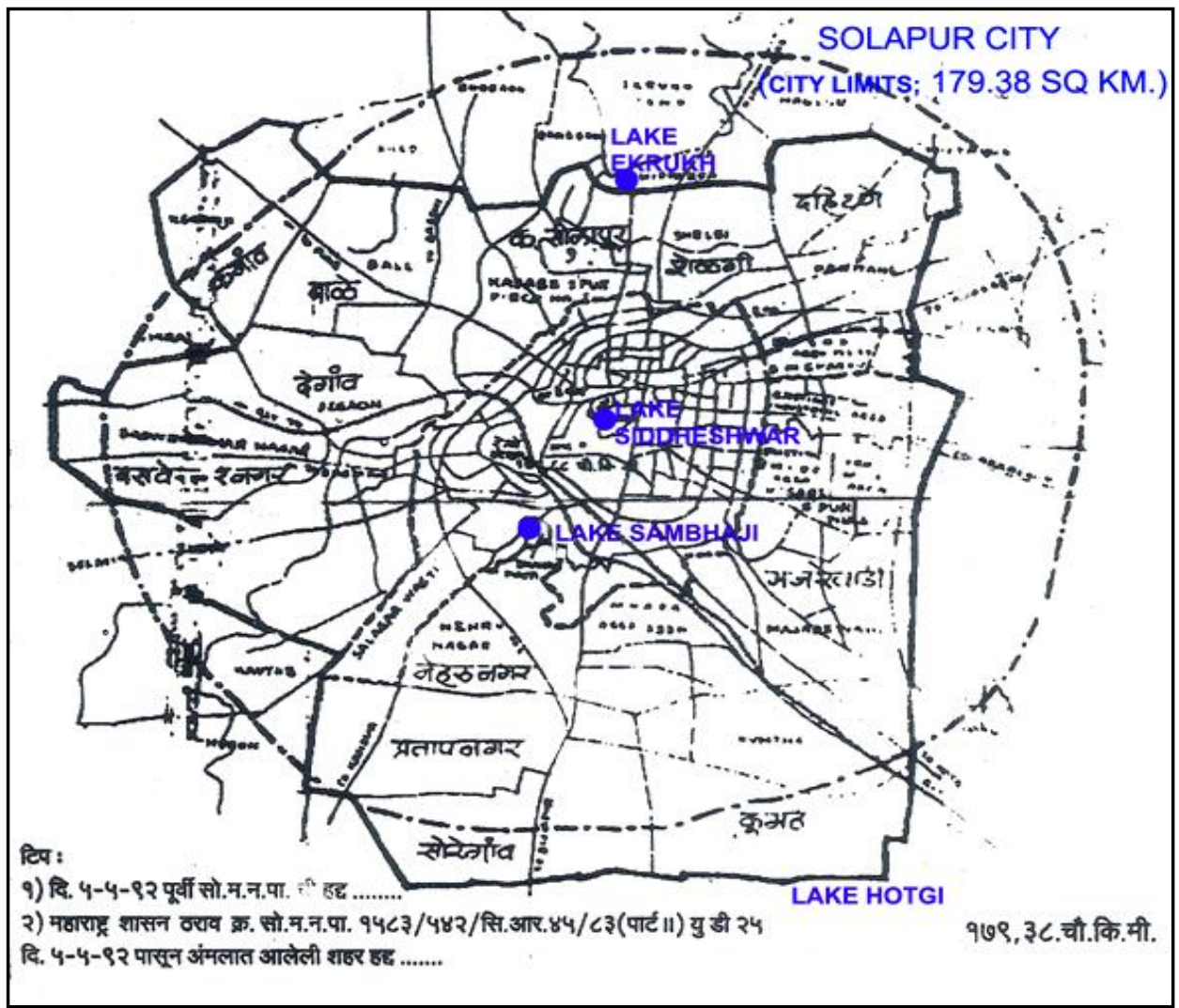

FIG 16:- City limits of Solapur with marked loci for lakes under study. 


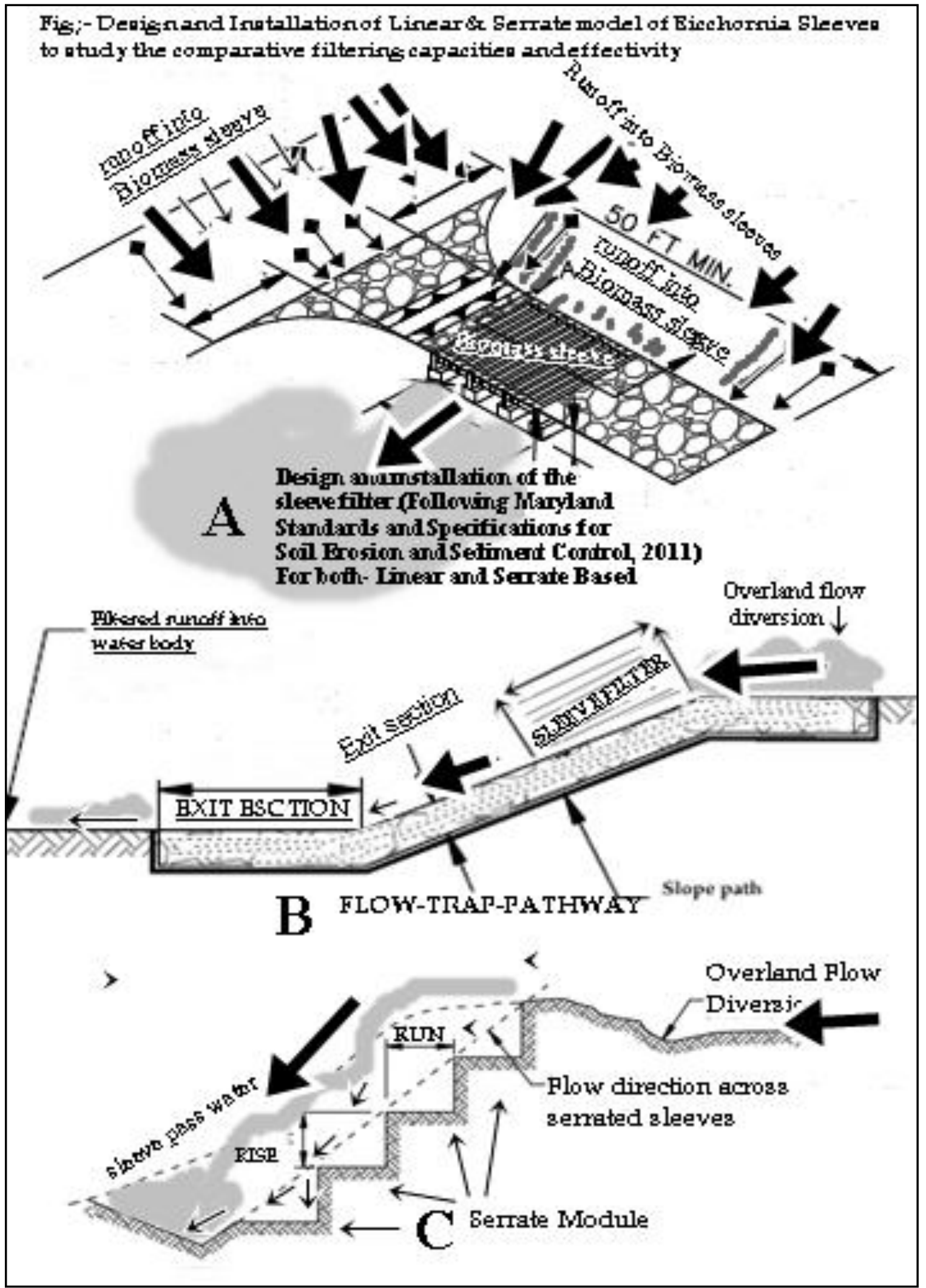

Fig 17:- Design and installation of Linear and serrate based Eicchornia Sleeve models To study comparative filtering capacities and effectiveness. 
Turbidity was analyzed by the nephelometric method, For the analysis of the total suspended solids and total dissolved solids following method was adopted- Before starting the test, the filters were washed with three successive $20 \mathrm{ml}$ portions of reagent-grade water through the vacuum filtering apparatus. The washed filters were then placed in well labeled aluminum weighing dishes and kept in the oven for drying to measure the total suspended solids. A separate set of well labeled aluminum weighing dishes was kept in the oven for measuring the total dissolved solids. Before commencement of the test, the weighing dishes (with and without the filters) were removed from the oven and cooled in desiccators before weighing. The weights of the weighing dishes (with and without the filters) were recorded as B1 and B2, respectively. A $25 \mathrm{ml}$ portion of the sample was measured using a pipette and deposited on the filter. Vacuum was applied, and the sample was allowed to pass through the filter. A 10 $\mathrm{ml}$ volume of the filtrate was pipetted into the weighing dishes (without the filter). The filters were removed from the filtering setup and placed in their respective weighing dishes. The dishes were then kept in the oven at $108^{\circ} \mathrm{C}$ to dry. On drying, the weighing dishes were removed from the oven, cooled in desiccators, and weighed. The weights of the weighing dishes (with and without the filters) were recorded as A1 and A2, respectively. The total suspended solids were then calculated using the following formula:

$$
m g \text { total suspened solids } / \text { liter }=\frac{(A 1-B 1) \times 1000}{25}
$$

The total dissolved solids were calculated using the formula:

$m g$ total dissolved solids $/$ liter $=\frac{(A 2-B 2) \times 1000}{10}$

\section{Results and Discussions:-}

In the earlier studies and published article regarding the design, installation and analysis of linear based Eicchornia sleeve, it was found that the efficacy of the model was analyzed to be successful in preventing sediment inflows at the lake waters. Effectively percent reduction of sand $89 \%$, TSS $68 \%$, silt $56 \%$, turbidity $51 \%$, and clay by $18 \%$ was recorded. This describes the effectual exploitation of the notorious weed Eicchornia biomass sleeve towards reducing sediments and turbidity of runoff waters entering the lake waters enhancing the ecological status of the lakes. As a part of extended study, the serrated model was employed and it resulted in percent reduction of sand $90 \%$, TSS $72 \%$, silt $69 \%$, turbidity $62 \%$, and clay by $28 \%$ (Table-2, Fig. 17). The serrate based application of the sleeve did not show any significant increase in the sand filtration in comparison with the linear based model. The serrate based model resulted in a increase in the percent reduction of total suspended solids, slit, turbidity and comparatively more of clay. The probable reason confirmed is due to the increase in the runoff slope length. Thus it can be concluded that the serrate mode of application of Eicchornia biomass sleeve is more effective in comparison with the earlier linear based model. The studies portray the application of the Eicchornia sleeve in high reduction in total suspended solids and sand. However this forced us to study the same sleeve application in a serrate manner to analyze the impact. The results portray encouraging results with an increased reduction in comparison to the linear based sleeve. However the studies of soluble pollutants shall be the further contemplation.

Table 2:- Impact of Linear based and serrate models of Eicchornia sleeve application.

\begin{tabular}{|l|l|l|}
\hline \multirow{2}{*}{$\begin{array}{l}\text { Decisive } \\
\text { factor }\end{array}$} & $\%$ Reduction $(\downarrow)$ & $\begin{array}{l}\text { Serrate based } \\
\text { Eicchornia } \text { sleeve }\end{array}$ \\
\cline { 2 - 3 } & $\begin{array}{l}\text { Linear based } \\
\text { Eicchornia Sleeve }\end{array}$ & $\mathbf{7 2}$ \\
\hline TSS & 68 & 62 \\
\hline Turbidity & 51 & 69 \\
\hline Silt & 56 & 90 \\
\hline Sand & $\mathbf{8 9}$ & 28 \\
\hline Clay & 18 & \\
\hline
\end{tabular}




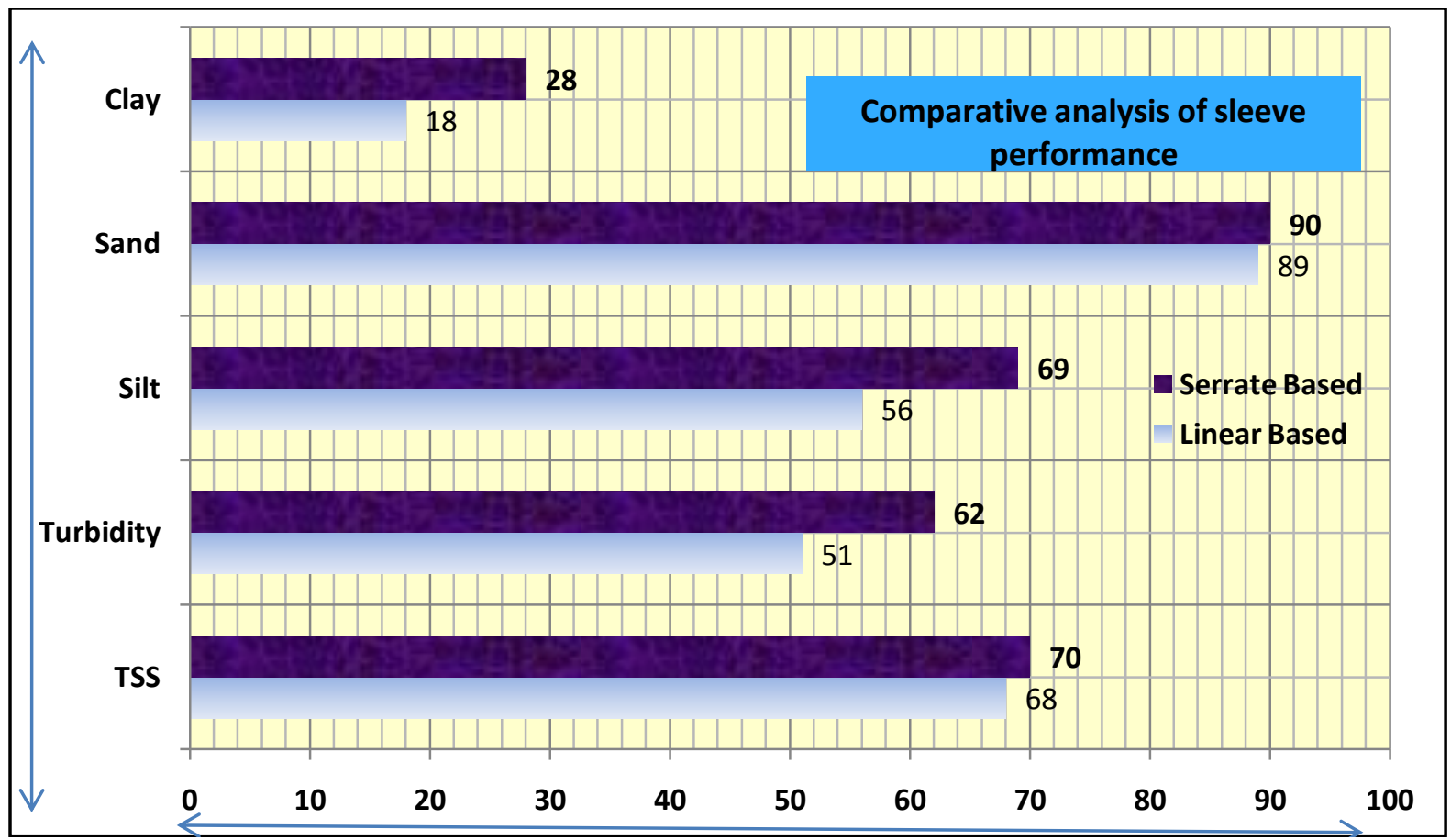

Fig 17:- Comparative analysis of effectiveness of linear based and serrate based Eicchornia biomass filters.

\section{Conclusions:-}

The serrate based model exhibited good performance where it resulted in a slight increase in the total suspended solids, slit, turbidity and comparatively more of clay. This could be attributed to the fact of the augmentation of the slope length. Thus it can be concluded that the serrate mode of application of Eicchornia biomass sleeves are more effective as compared with the linear based. However we arrive at a conclusion that the selection and application of the linear based or serrate based Eicchornia biomass sleeves should be site specific. Either of the methods shows a promising reduction in the silt loads into the lake waters. The application of Eicchornia sleeves also prove to be effective in put off the off-site runoff, they should therefore further be treated of importance towards stabilization matrices for soils along the sites. The serrate based application of the sleeve did not show any significant increase in the sand filtration in comparison with the linear based model. The moderate performance of the linear based sleeves could be attributed to the fact that the water was either overtopping on the clay or under-flowing on sand with respect to the sleeve. However the sleeves should considerably prove to be helpful to remove sediment from runoff and avoid adding it to the water bodies acting as a sediment trap, slowing the runoff velocity and allowing sediment to settle out reducing off-site sediment loss. The site specific sleeve installations can effectively be recommended for the perimeter protection and for the toe-of-slope or mid-slope sediment control practices. The remarkable importance of the application of the biomass sleeves is because of the ability to physically hold the soil in place facilitating the erosion control and increasing the rates of infiltration or seepage by enhancing the soil structure and porosity. The Eicchornia biomass sleeve application should emerge as a novel, cost effective, and environmentally friendly method of silt filtration. However the functional longevity of the sleeve design is projected to about 6-8 months. However this can be effectively practiced during the rainy season, which lasts here for a very short time, since the study area is arid.

\section{Limitations:-}

Although the filter sleeve was found to be fairly adaptable, this management practice has certain limitations. If the quality of the compost of the biomass used is not sustained, particularly for the particle size distribution and also the biological stability, the efficacy possibly will severely be diminished. For inappropriately prepared land surface, the Eicchornia biomass filter sleeve shall not serve the designated purpose. This condition may allow untreated inlet flow. Eicchornia biomass filter sleeves cannot be placed in perennial streams since clogging may interrupt the filtration capability. Mechanical movement over the filter sleeves may diminish the field performance and capacity of the sleeves. The clogging rate and the effectiveness of the sleeve after clogging are yet to be studied. 


\section{Acknowledgement:-}

We express our gratitude to Dr. E. Elango Scientist, NRSC, Dept. of Space, Govt. of India, Hyderabad, A.P. for providing the requisite imageries \& long-term consultation for the successful completion of project. We further extend our appreciation to the Principal, Walchand College of Arts \& Science for his keen interest and continuous guidance for the research activities. We also thank Mr. Rajesh Moholkar for aiding the design, layout and installation programme. With sincere expectations that the studies shall be a continued effort for our project to extend advanced scientific studies to enrich, improve and focus on priority the sites for detailed inventories in the proposed subsequent phase.

\section{References:-}

1. Beverly B. Storey, et. al. Compost filter berms; are they the organic BP solutions?

2. Hawley et. al. 1989, Channel Evolution Model (CEM), Stream Dynamics Fact Sheet - May 2003, http://www.nrcs.usda.gov/wps/portal/nrcs/detail/il/home/?cid=nrcs141p2_031337

3. Simon, 1989, Channel Evolution Model of Semiarid Stream Response to Urban-Induced Hydromodification, 2012 , (JAWRA) 1-23. DOI: 10.1111/j.1752-1688.2012.00645.x Journal of the American Water Resource Association.

4. David H. McNabb and Frederick J. Swanson ; Effects of Fire on Soil Erosion; http://andrewsforest.oregonstate.edu/pubs/pdf/pub1055.pdf

5. Demars, K., R. Long, and J. Ives. November 2001. "Using woody material for erosion control." Biocycle. Vol. 42, No. 11, p 44-45.

6. Foster, G. R. 1982. Modeling the erosion process. In: Haan, C. T.; Johnson, H. P.; Brakensiek, D. L., eds. Hydrologic modeling of small watersheds. St. Joseph, MI: American Society of Agricultural Engineers: chapter 8.

7. Glanville, T. D., R. A. Persyn, and T. L. Richard. 2001.'Impacts of Compost Application on Highway Construction Sites in Iowa." Paper No. 01-2076, ASAE, St. Joseph, Mich.

8. Guidelines for sediment control practices in the insular Caribbean- - Sandra Elaine Stevenson, (UNEPCaribbean Environment Programme); CEP Technical Report No. 32, 1994. http://www.ieca.org/membersonly/cms/content/Proceedings/Object396PDFEnglish.pdf

9. Iowa Construction Site Erosion Control Manual, Iowa Department of Natural Resources (IDNR), 2006.

10. Kaufman, M. M. 2000. "Erosion control at construction sites: The science-policy gap." Environmental Management. Vol. 26, No. 1, p 89-97.

11. Maryland Department of the Environment, Water Management Administration. 1994. Maryland Standards and Specifications for Soil Erosion and Sediment Control, Annapolis,

12. Maryland. In cooperation with USDA Soil Conservation Service.Maryland Standards and Specifications for Soil Erosion and Sediment Control, 2011.

13. Risse, M., and B. Faucette. 2003. "Compost utilization for erosion control." Cooperative Extension Service: The University of Georgia, College of Agriculture and Environmental Sciences. http://pubs.caes.uga.edu/caespubs/pubs/PDF/

14. Shekhar Salunke, Chavan B.L. 2016, Evaluating efficacy of conceptual sediment barrier matrix towards ecosystem restoration attributes, IJRET: International Journal of Research in Engineering and Technology.

15. Smith, R. R. 2002. "New erosion control methods using compost made easy." Land and Water, July/August, p 38-41.

16. Storey, B. B., J. A. McFalls, and S. H. Godfrey. 1996."The Use of Compost and Shredded Brush on Rightsof-Way for Erosion control: Final Report.” Research Report 1352-2F, Texas Transportation Institute.

17. Technical note 1, May 2008, Stream Water Surface Profile Modification for Wetland Restoration, United States Department of Agriculture, Natural Resource Conservation Service, www.nrcs.usda.gov/wps/PA_NRCSConsumption/download?cid

18. Tyler, R. 2000. "Compost filter berms and blankets take on the silt fence." Biocycle, January, p 59-62.

19. U.S. Army Corps of Engineers, Waterways Experiment Station, Wetlands Research Program. 1987. Corps of Engineers Wetlands Delineation Manual. Technical Report Y-87-1. Vicksburg, MS.

20. U.S. Environmental Protection Agency. 2006. National Pollutant Discharge Elimination System, Phase II. Compost Filter Socks: Construction Site Stormwater Runoff Control. National Menu of Best Management Practices for Construction Sites. http://cfpub.epa.gov/npdes/stormwater/menuofbmps/index.cfm?action=factsheet_results\&view=specific\&b $m p=120$ ). 